\title{
Analysis of the dynamics of venous blood flow in the context of lower limb temperature distribution and tissue composition in the elderly
}

This article was published in the following Dove Press journal:

Clinical Interventions in Aging

28 August 2017

Number of times this article has been viewed

\author{
Aleksandra Skomudek ${ }^{1,2}$ \\ Iwona Gilowska 1,3 \\ Ryszard Jasiński ${ }^{4}$ \\ Krystyna Rożek-Piechura ${ }^{4}$ \\ 'Department of Physical Education \\ and Physiotherapy, Opole \\ University of Technology, Opolskie, \\ ${ }^{2}$ Department of Clinical Physiotherapy, \\ ${ }^{3}$ Department of Biochemistry \\ and Physiology, ${ }^{4}$ Department of \\ Physiotherapy and Occupational \\ Therapy in Conservative and \\ Interventional Medicine, University \\ of Physical Education in Wroclaw, \\ Wroclaw, Poland
}

Objective: The elderly are particularly vulnerable to degenerative diseases, such as circulatory and respiratory system and vascular system diseases. The objective of this study was therefore to evaluate the distribution of temperature and the dynamics of venous blood flow in the lower limbs (LLs) and to assess the interdependence of these parameters in terms of the somatic components in males and females participating in activities at the University of the Third Age.

Materials and methods: The study included 60 females (mean age 67.4 years) and 40 males (mean age 67.5 years). A body composition assessment was performed using the bioimpedance technique - Tanita BC-418MA. The following parameters were examined: fat $\%$, fat mass, fatfree mass, and total body water. The minimal, maximal, and mean temperature values and their distributions were examined using infrared thermographic camera VarioCAM Head. Measurements of the venous refilling time and the work of the LL venous pump were examined using a Rheo Dopplex II PPG.

Results: In males, the mean value of the right LL temperature was 30.58 and the mean value of the left LL was 30.28; the $P$-value was 0.805769 . In females, the mean value of the right LL temperature was 29.58 and the mean value of the left limb was 29.52 ; the $P$-value was 0.864773. In males, the right limb blood flow was 34.17 and the left limb blood flow was 34.67 ; the $P$-value was 0.359137 . In females, the right limb blood flow was 26.89 and the left limb blood flow was 26.09; the $P$-value was 0.796348 .

Conclusion: Research results showed that the temperature distribution and the dynamics of blood flow are not significantly different between the right and left extremities in both males and females. However, significant temperature differences were found between the gender groups. Significantly higher temperature values in both the right and left extremities were recorded in males than in females.

Keywords: thermovision, lower limb, blood circulation

\section{Introduction}

The elderly are particularly vulnerable to degenerative diseases, such as circulatory and respiratory system and vascular system diseases. Many researchers have drawn attention to the problem concerning the venous system, which is manifested in the form of dysfunctions of the work of venous valves. ${ }^{1-4}$ Based on the studies, the risk factors for cardiovascular diseases include heredity, age, female gender, obesity, pregnancy, and height. ${ }^{5-9}$

Bagvathiappan et al (2009) confirmed the potential of using thermal imaging for medical diagnosis, in cases related to vascular disorders. The temperature in limb regions affected by vascular disorders was lower because of artery occlusion; however,
Correspondence: Aleksandra Skomudek Faculty of Physical Education and Physiotherapy, Opole University of Technology, ulica Proszkowska 76, 45-758 Opole, Opolskie, Poland Email a.skomudek@po.opole.pl 
in some areas, a temperature increase was recorded, which was due to inflammatory changes and vein inflammation. ${ }^{10}$

The difference in temperature is associated with an impaired blood supply to the examined area of the body, indicating blood flow impairment. ${ }^{10-12}$ Superficial temperature changes may provide information on the efficacy of the system, endogenously removing heat generated during exercise, as well as metabolic changes associated with body homeostasis after the exercise. Efficiency of the thermoregulatory system is an important element reflecting the adaptation capacity for physical activity, exercise tolerance, as well as fitness. ${ }^{13}$

Many researchers attempted to assess the dynamics of venous blood flow in the extremities. A noninvasive test known as reography can evaluate the quality of venous blood flow in the veins as well as the work of the venous pump (VP). It uses infrared light emission to the dermis, acting by reflecting off the cellular components and returning to the sensor. ${ }^{14-17}$ The aforementioned studies report the use of reography in venous diseases, specifically venous reflux. The work of the VP in lower extremities is extremely important in assisting drainage of venous blood from the lower extremities, thus preventing blood retention and reflux. The dysfunction or impaired working of the valves or muscle weakness in the calf can cause chronic venous disorders (CVD). ${ }^{3,18-21}$

The quest for relationships between the distribution of temperature and the dynamics of venous blood flow in lower extremities and the somatic features of elderly people is therefore of interest. The objective of this study was therefore to evaluate the distribution of temperature and the dynamics of venous blood flow in the lower limbs (LLs) and to assess the interdependence of these parameters in terms of the somatic components in males and females participating in the University of Third Age activities.

The following research questions were presented:

1. Do the distribution of temperature and the dynamics of blood flow differ between the right and left limbs in gender groups?

2. Is there a correlation between the temperature distribution in the lower legs and the work of the LL VP and venous refilling time $(\mathrm{RT})$ ?

3. Do somatic parameters have a relationship with mean temperature of the area and the dynamics of blood flow in patients?

Hypothesis: The distribution of temperature and the dynamics of venous blood flow do not differ between the right and left limbs in male and female groups. The temperature value depends on the work of the VP and the venous RT as well as the somatic parameters.

\section{Materials and methods Study population}

The study group consisted of 60 females (mean age 67.4 years) and 40 males (mean age 67.5 years), who were students of the University of Third Age in Opole, Poland. All patients gave informed consent to take part in the research. The most common comorbidities in the examined group were hypertension, osteoarthritis, and osteoporosis. The study was conducted between February and March 2015. The research protocol was approved by the Senate Ethics Committee for Scientific Research of the University of Physical Education in Wroclaw. The following data were collected: age, height, weight, and body mass index (BMI), ie, body mass (kg)/ body height $\left(\mathrm{m}^{2}\right)$.

The following measurements were assessed: body composition analysis using the bioimpedance technique, the distribution of temperature, and the dynamics of venous blood flow in lower extremities. Tests were performed before noon by the same person. All subjects were familiarized with test procedures and methods in advance. Information was kept confidential, and participants had the right to withdraw at any stage of the research.

\section{Body composition analysis}

The Tanita BC-418MA was used for segmental body composition analysis. This device was equipped with eight electrodes allowing a very accurate calculation of fat and muscle tissue in specific segments of the body (left leg, left arm, right leg, right arm, and torso). The four electrodes were mounted to the platform on which the test person was standing. The next four electrodes were in the holders held by the participant in his hands. The upper limbs were loosely hanging down the trunk.

The following parameters were put to analyses:

- Total body weight $\%$ (fat $\%$ )

- Total weight of fat mass in kilograms (fat mass)

- Fat-free mass (FFM)

- Total body water (TBW)

Furthermore, the following parameters have been determined for the body segments, ie, the LLs: fat $\%$, fat mass, and FFM.

\section{Study of temperature distribution in LLs}

Thermography tests were carried out in a separate room where constant temperature and humidity were maintained, respectively, at $25^{\circ} \mathrm{C}$ and $45 \%$. The measuring position was equipped with the following devices:

- Infrared thermographic VarioCAM Head camera with a $320 \times 240$ pixel resolution, 


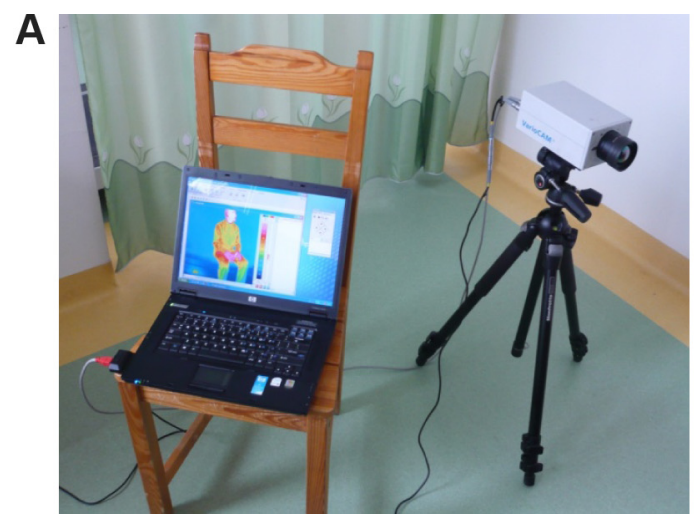

Figure I Thermal imaging equipment and temperature distribution in the lower limb. Notes: (A) Measuring station. (B) Obtained thermogram.

- Portable computer with IRBIS 3 Professional thermography software from Intra Tec GmbH (Dresden, Germany)

- Thermometer for measuring the temperature in the room

- Hygrometer to measure the humidity in the room

In order to ensure proper working conditions of the thermal imaging camera, we turned it on $\sim 30$ minutes before the first measurement. During tests, the camera was positioned at a fixed distance from the subject $(150 \mathrm{~cm})$. The measurement of temperature distribution entailed the right and left medial LLs from medial ankle to the knee joint.

The minimum, maximum, and mean temperature values were determined based on the thermal images obtained (Figure $1 \mathrm{~A}$ and $\mathrm{B}$ ).

\section{Dynamics of venous blood flow in lower extremities}

A venous photoplethysmography (PPG) of the LLs was also performed as a part of the research. Measurements of the RF and VP of the LL were taken during an examination of venous blood flow of the LLs (reography) using a Rheo Dopplex II PPG device from Huntleigh Diagnostics (Cardiff, UK). Measurements of the venous RT and the work of the LL VP were
B

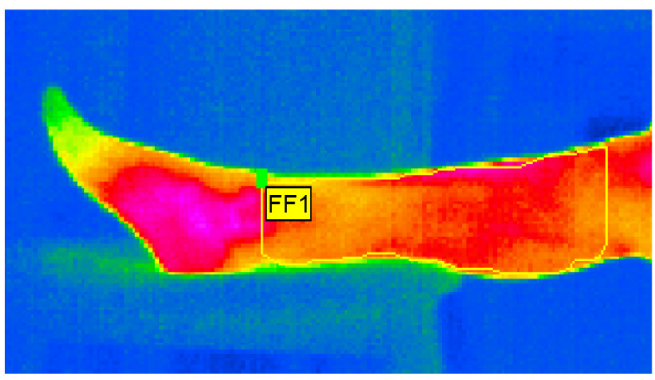

taken. The irregularities in venous circulation were shown by the RF parameter, which for lower extremities should have a value of $>45$ seconds, while the value of the VP parameter of a healthy individual should be $\geq 40$ seconds. Measurements were made three times separately for the right (R RT and R VP) and left (L RT and L VP) LLs (Figure 2A and B). The participant was sitting on a chair, and LLs bent at the knee joint at $\sim 110^{\circ}$, with feet flat on the floor. A photoplethysmographic sensor was attached $10 \mathrm{~cm}$ above the medial ankle. The participant made 10 rhythmic dorsiflexions of the foot (blood outflow occurring), followed by 45 seconds of remaining motionless (veins filling up with blood). The apparatus registered the VP and RT parameters from the first dorsiflexion of the foot. In the first place, a curve was obtained showing blood pumped out from the foot area and lower leg and then a slow blood fall, indicating its return to the LL venous system.

The results were analyzed using the Statistica Version 10 package from StatSoft (Krakow, Poland). The normality of distribution of examined parameters was analyzed using a Shapiro-Wilk test. Descriptive statistics were presented as mean and standard deviation. The differences between gender groups were analyzed using Student's $t$-test for independent samples. Statistical significance was determined at $P<0.05$.
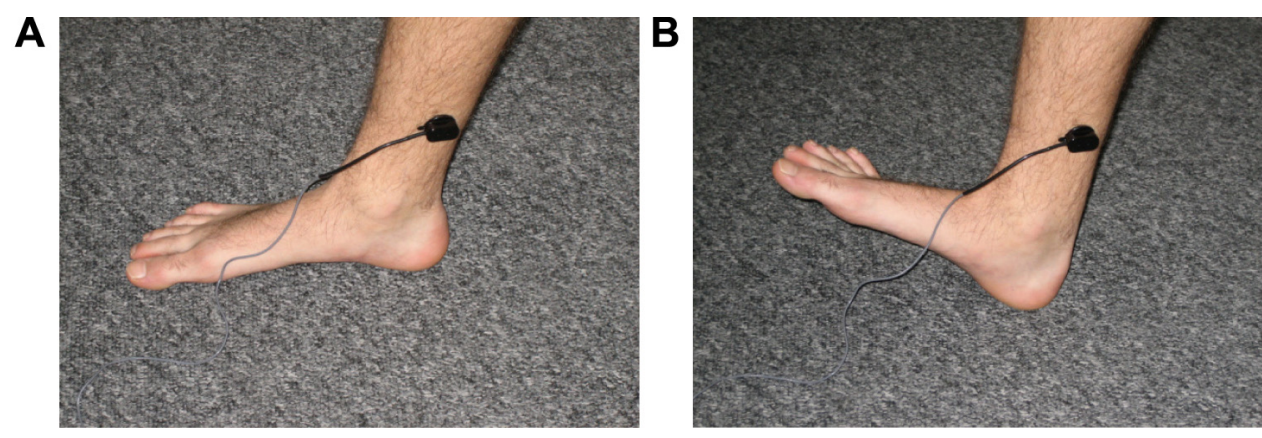

Figure 2 Study of venous blood flow of lower limbs.

Note: (A and $\mathbf{B})$ Positioning of the sensor and dorsiflexion of the ankle joint. 
A Brown-Forsyth test was used for the comparison of results between the right and left limbs. Spearman's rank correlations were used to demonstrate correlation between parameters.

\section{Results}

\section{Participants}

It was found that the treatment groups were homogeneous with respect to age and BMI (Table 1).

Body fat analysis based on BMI showed a similar distribution of overweight and obesity in both groups, and the difference is that more women are overweight compared to more obese men (Figure 3 ).

\section{Thermographic and reographic parameters in the examined groups}

The results of the dynamics of venous blood flow in LLs in the study group revealed that the value of venous RT (seconds) for the right and left limbs in females was higher than in males. In contrast, the values of VP parameters for both the left and right limbs were higher in males (Table 2).

\section{Correlation for males and females for the thermal imaging study}

Table 3 shows the Spearman's rank correlation coefficient $(\rho)$ of the group for the thermal imaging study of extremities with venous blood flow results. The data reveal that in the case of males, the mean temperature value indicated in the left limb correlates significantly with the RT parameter specified for the right limb, whereas in the case of females, the situation is

Table I Detailed characteristics of the examined groups

\begin{tabular}{|c|c|c|c|}
\hline \multirow[t]{2}{*}{ Variables } & \multirow{2}{*}{$\frac{\text { Female }}{\text { Mean } \pm \text { SD }}$} & \multirow{2}{*}{$\frac{\text { Male }}{\text { Mean } \pm \text { SD }}$} & \multirow[t]{2}{*}{$P$-value } \\
\hline & & & \\
\hline Age (years) & $67.4 \pm 5.00$ & $67.53 \pm 5.91$ & 0.963966 \\
\hline Body height $(\mathrm{cm})$ & $161 \pm 5.79$ & $172 \pm 4.46$ & 0.000000 \\
\hline Body mass (kg) & $71.77 \pm 10.78$ & $85.39 \pm 12.1$ & 0.000000 \\
\hline $\mathrm{BMI}\left(\mathrm{kg} / \mathrm{m}^{2}\right)$ & $27.56 \pm 3.24$ & $28.9 \pm 4.25$ & 0.076755 \\
\hline TBW (\%) & $33.39 \pm 3.12$ & $45.64 \pm 4.43$ & 0.000000 \\
\hline Body fat (\%) & $35.67 \pm 5.56$ & $26.38 \pm 6.03$ & 0.000000 \\
\hline FFM (\%) & $45.6 \mathrm{I} \pm 4.26$ & $62.34 \pm 6.04$ & 0.000000 \\
\hline Impedance right leg & $242.15 \pm 28.34$ & $217.35 \pm 32.63$ & 0.000103 \\
\hline Impedance left leg & $241.16 \pm 26.69$ & $223.13 \pm 31.48$ & 0.002585 \\
\hline FFM right leg (\%) & $7.56 \pm 0.79$ & $10.32 \pm 1.14$ & 0.000000 \\
\hline FFM left leg (\%) & $7.47 \pm 0.76$ & $10.16 \pm 1.17$ & 0.000000 \\
\hline Fat right leg (\%) & $40.62 \pm 4.50$ & $23.57 \pm 5.74$ & 0.000000 \\
\hline Fat left leg (\%) & $40.95 \pm 3.86$ & $23.8 I \pm 5.6 I$ & 0.000000 \\
\hline
\end{tabular}

Notes: Data in bold indicates statistical significance at $P<0.05$.

Abbreviations: BCM, body cell mass; BMI, body mass index; FFM, fat-free mass; $\mathrm{SD}$, standard deviation; TBW, total body water.

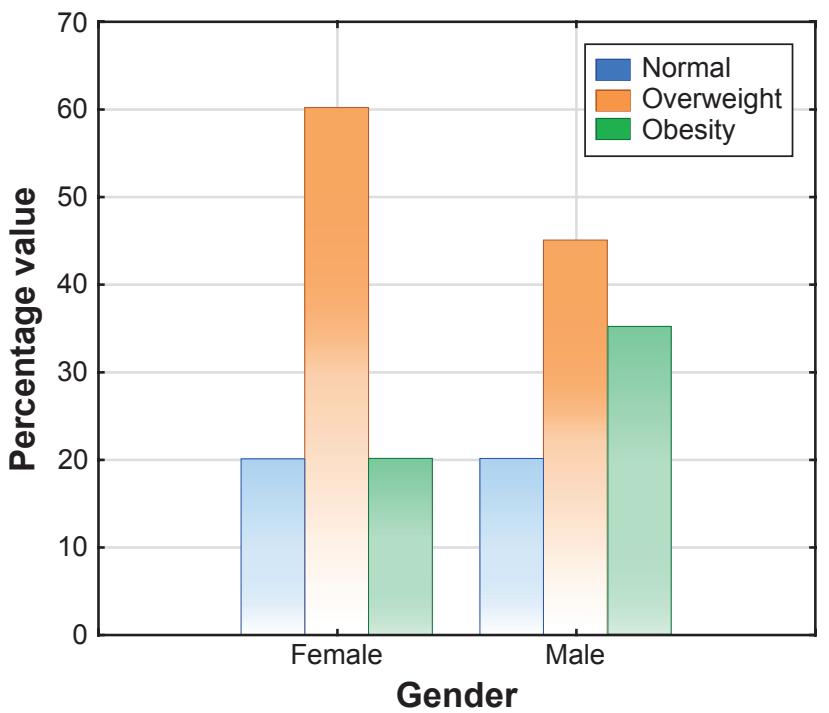

Figure 3 Characteristics of BMI in males and females. Abbreviation: BMI, body mass index.

reversed, ie, the value of mean temperature in the right limb also correlates significantly with the RT parameter.

\section{Correlation for males and female for the reographic study}

Tables 4 and 5 present data illustrating the degree of interrelationship between the dynamics of venous blood flow in LLs with respect to the groups' somatic characteristics. In evaluating the RT and VP parameters determining the dynamics of blood flow in LLs, with somatic characteristics, an observation was made in the group of males, showing that the VP parameter of the right LL only correlates significantly with the whole-body impedance parameter and the right LL impedance parameter.

Table 2 Characteristics of thermographic and reographic parameters in the examined groups

\begin{tabular}{|c|c|c|c|}
\hline \multirow[t]{2}{*}{ Variables } & \multirow{2}{*}{$\frac{\text { Male }}{\text { Mean } \pm \text { SD }}$} & \multirow{2}{*}{$\frac{\text { Female }}{\text { Mean } \pm \text { SD }}$} & \multirow{2}{*}{$\begin{array}{l}\text { P-value } \\
\text { between } \\
\text { groups }\end{array}$} \\
\hline & & & \\
\hline Temperature right lower limb & $30.58 \pm 0.86$ & $29.58 \pm 1.26$ & 0.000028 \\
\hline Temperature left lower limb & $30.28 \pm 0.83$ & $29.52 \pm 1.18$ & $0.00077 \mid$ \\
\hline$P$-value within groups & 0.805769 & 0.864773 & \\
\hline RT right lower limb & $31.04 \pm 13.07$ & $33.68 \pm|0.7|$ & 0.270773 \\
\hline RT left lower limb & $30.04 \pm 11.5$ & $31.16 \pm 11.59$ & 0.634242 \\
\hline$P$-value within groups & 0.979446 & 0.149010 & \\
\hline VP right lower limb & $34.17 \pm 11.29$ & $26.89 \pm 8.06$ & 0.000170 \\
\hline VP left lower limb & $34.67 \pm 10.33$ & $26.09 \pm 8.41$ & 0.000014 \\
\hline$P$-value within groups & 0.359137 & 0.796348 & \\
\hline
\end{tabular}

Note: Data in bold indicates statistical significance at $P<0.05$.

Abbreviations: RT, refilling time; SD, standard deviation; VP, venous pump. 
Table 3 Spearman's rank correlation coefficient $(\rho)$ for males and females for the thermal imaging study

\begin{tabular}{|c|c|c|c|c|}
\hline \multirow[t]{2}{*}{ Variables } & \multicolumn{2}{|l|}{ Male } & \multicolumn{2}{|l|}{ Female } \\
\hline & $\begin{array}{l}\text { Mean temperature } \\
\text { value, right lower limb }\end{array}$ & $\begin{array}{l}\text { Mean temperature } \\
\text { value, left lower limb }\end{array}$ & $\begin{array}{l}\text { Mean temperature } \\
\text { value, right lower limb }\end{array}$ & $\begin{array}{l}\text { Mean temperature } \\
\text { value, left lower limb }\end{array}$ \\
\hline Age & -0.164645 & -0.196568 & 0.023735 & 0.067969 \\
\hline RT right lower limb & -0.219490 & -0.344429 & -0.233462 & -0.203334 \\
\hline VP right lower limb & 0.108905 & 0.046564 & 0.159831 & 0.182698 \\
\hline RT left lower limb & $-0.0575 \mid 4$ & -0.095332 & $-0.26096 \mathrm{I}$ & -0.136122 \\
\hline VP left lower limb & -0.014566 & -0.101208 & -0.156239 & -0.128130 \\
\hline BMI & -0.004128 & -0.259793 & -0.073173 & $-0.08|4| I$ \\
\hline Fat\% right & -0.019044 & $-0 .|73| 7 \mid$ & -0.106366 & -0.113705 \\
\hline Fat mass right & 0.008269 & -0.173268 & -0.048093 & -0.03585 I \\
\hline FFM right & 0.104220 & -0.050418 & 0.007510 & -0.005788 \\
\hline Muscle right & 0.105100 & -0.056257 & 0.011113 & -0.007060 \\
\hline Fat\% left & 0.017638 & $-0.16|17|$ & -0.053397 & -0.112757 \\
\hline Fat mass left & 0.016342 & -0.173836 & -0.050359 & -0.044482 \\
\hline FFM left & 0.121231 & -0.084261 & -0.016183 & 0.045634 \\
\hline Muscle left & 0.112385 & $-0.094|5|$ & -0.018324 & 0.040940 \\
\hline Impedance whole body & 0.008117 & 0.112513 & -0.125593 & -0.124891 \\
\hline Impedance right leg & 0.050080 & 0.196743 & $-0.07540 \mathrm{I}$ & -0.042196 \\
\hline Impedance left leg & 0.039191 & 0.122495 & 0.077288 & $0.02428 \mathrm{I}$ \\
\hline
\end{tabular}

Note: Data in bold indicates statistical significance at $P<0.05$.

Abbreviations: BMI, body mass index; FFM, fat-free mass; RT, refilling time; VP, venous pump.

In females, the RT parameter of the right LL showed significant correlation with the impedance parameter of the left LL. The work of the VP in the lower right limb significantly correlated with the total weight of fat mass right LL, FFM right LL, and muscle mass of the right LL. Moreover, the investigated parameter correlated with the total weight of fat mass left LL, FFM left LL, and muscle mass of the left LL. In the case of VP for the left lower extremity, there was a correlation with FFM right LL, muscle mass of the right LL, as well as FFM and muscle mass of the left lower extremity.
A statistically significant correlation of age with the work of the VP of the LL was only observed in the group of females. The other significant correlations concerned BMI with the majority of body composition parameters in both females and males (Table 6).

When analyzing the results of the male and female groups, it has been observed that the differences in mean of all the variables in the left and right LL groups were not statistically significant. Theoretical implications of the lack of differences in the distribution of temperature and quality of blood flow in lower extremities in elderly males and females are confirmed

Table 4 Spearman's rank correlation coefficient $(\rho)$ for males for the reographic study

\begin{tabular}{|c|c|c|c|c|}
\hline Variables & $\begin{array}{l}\text { RT right } \\
\text { lower limb }\end{array}$ & $\begin{array}{l}\text { VP right } \\
\text { lower limb }\end{array}$ & $\begin{array}{l}\text { RT left } \\
\text { lower limb }\end{array}$ & $\begin{array}{l}\text { VP left } \\
\text { lower limb }\end{array}$ \\
\hline BMI & 0.101616 & -0.135393 & -0.009563 & 0.106720 \\
\hline Fat right lower limb & 0.048309 & 0.064307 & -0.212722 & 0.085326 \\
\hline Fat mass right lower limb & 0.054901 & 0.047957 & -0.187090 & 0.155450 \\
\hline FFM right lower limb & 0.109999 & -0.129851 & 0.077553 & 0.047073 \\
\hline Muscle right lower limb & 0.112411 & -0.132102 & 0.072270 & 0.047747 \\
\hline Fat\% left lower limb & $-0.00707 \mid$ & 0.061728 & -0.189585 & 0.122780 \\
\hline Fat mass left lower limb & 0.045133 & 0.023167 & -0.189173 & 0.163366 \\
\hline FFM left lower limb & 0.165416 & -0.054336 & 0.108260 & 0.089724 \\
\hline Muscle left lower limb & 0.172545 & -0.048474 & 0.103170 & 0.091491 \\
\hline Impedance whole body & 0.039021 & 0.401136 & -0.087598 & 0.156045 \\
\hline Impedance right leg & 0.003799 & $0.34|27|$ & -0.086533 & 0.115985 \\
\hline Impedance left leg & -0.069279 & 0.305669 & -0.129587 & 0.169488 \\
\hline
\end{tabular}

Note: Data in bold indicates statistical significance at $P<0.05$.

Abbreviations: BMI, body mass index; FFM, fat-free mass; RT, refilling time; VP, venous pump. 
Table 5 Spearman's rank correlation coefficient $(\rho)$ for females for the reographic study

\begin{tabular}{|c|c|c|c|c|}
\hline Variables & $\begin{array}{l}\text { RT right } \\
\text { lower limb }\end{array}$ & $\begin{array}{l}\text { VP right } \\
\text { lower limb }\end{array}$ & $\begin{array}{l}\text { RT left } \\
\text { lower limb }\end{array}$ & $\begin{array}{l}\text { VP left } \\
\text { lower limb }\end{array}$ \\
\hline BMI & 0.054732 & 0.221366 & 0.006489 & 0.140708 \\
\hline Fat right lower limb & -0.031260 & $0.207 \mid 46$ & 0.026062 & 0.074055 \\
\hline Fat mass right lower limb & 0.052343 & 0.282565 & 0.058747 & 0.154510 \\
\hline FFM right lower limb & 0.226050 & 0.286794 & 0.104604 & 0.320101 \\
\hline Muscle right lower limb & 0.220325 & 0.267608 & 0.095331 & 0.316404 \\
\hline Fat left lower limb & -0.052757 & 0.162654 & -0.068407 & 0.056808 \\
\hline Fat mass left lower limb & 0.075379 & 0.282474 & 0.042835 & 0.176770 \\
\hline FFM left lower limb & 0.205147 & 0.332785 & 0.130106 & 0.262835 \\
\hline Muscle left lower limb & 0.205933 & 0.34362 I & 0.111236 & 0.260047 \\
\hline Impedance whole body & -0.132584 & -0.030655 & -0.051625 & -0.156857 \\
\hline Impedance right leg & -0.117617 & 0.058017 & 0.088257 & -0.067242 \\
\hline Impedance left leg & -0.282516 & -0.088446 & $-0.12635 \mid$ & $-0.15|20|$ \\
\hline
\end{tabular}

Note: Data in bold indicates statistical significance at $P<0.05$.

Abbreviations: BMI, body mass index; FFM, fat-free mass; RT, refilling time; VP, venous pump.

by the results comparing the two groups in terms of the body's individual somatic components (Table 7).

There are no grounds to reject the hypothesis of equal population mean at the significance level $(\alpha=0.05)$.

\section{Discussion}

Based on own research results, a significant difference was found in the temperature values of both LLs between females

Table 6 Spearman's rank correlation coefficient $(\rho)$ for males and females

\begin{tabular}{|c|c|c|c|c|}
\hline \multirow[t]{2}{*}{ Variables } & \multicolumn{2}{|l|}{ Male } & \multicolumn{2}{|l|}{ Female } \\
\hline & Age & BMI & Age & BMI \\
\hline Age & 1.000000 & 0.327299 & 1.000000 & -0.223424 \\
\hline $\begin{array}{l}\text { Mean temperature } \\
\text { value, } R_{\mathrm{LL}}\end{array}$ & -0.164645 & -0.004128 & 0.023735 & -0.073173 \\
\hline $\begin{array}{l}\text { Mean temperature } \\
\text { value, } L_{\mathrm{LL}}\end{array}$ & -0.196568 & -0.259793 & 0.067969 & $-0.08|4| I$ \\
\hline RT right & -0.096678 & 0.101616 & -0.055347 & 0.054732 \\
\hline VP right & -0.227164 & -0.135393 & -0.269588 & 0.221366 \\
\hline RT left & -0.265049 & -0.009563 & -0.127255 & 0.006489 \\
\hline VP left & 0.122762 & 0.106720 & -0.155646 & 0.140708 \\
\hline BMI & 0.327299 & 1.000000 & -0.223424 & 1.000000 \\
\hline Fat right & 0.334165 & $0.57644 I$ & -0.233501 & $0.85028 I$ \\
\hline Fat mass right & 0.293547 & $0.74509 \mid$ & -0.312018 & 0.940734 \\
\hline FFM right & -0.058597 & 0.732288 & -0.303685 & 0.610949 \\
\hline Muscle right & -0.057768 & 0.732905 & -0.297748 & 0.618108 \\
\hline Fat left & $0.28734 \mid$ & 0.644680 & -0.161031 & 0.838653 \\
\hline Fat mass left & 0.271786 & 0.783075 & $-0.283|5|$ & 0.944438 \\
\hline FFM left & -0.023545 & 0.749343 & -0.343356 & 0.710344 \\
\hline Muscle left & -0.027273 & 0.755663 & -0.354913 & 0.716000 \\
\hline $\begin{array}{l}\text { Impedance whole } \\
\text { body }\end{array}$ & -0.175699 & -0.653590 & 0.109396 & $-0.33764 I$ \\
\hline Impedance right leg & -0.234096 & -0.618616 & 0.048752 & -0.4583 I 4 \\
\hline Impedance left leg & -0.190100 & -0.539382 & 0.033650 & -0.38455 I \\
\hline
\end{tabular}

Note: Data in bold indicates statistical significance at $P<0.05$.

Abbreviations: BMI, body mass index; FFM, fat-free mass; LL, lower limb; $\mathrm{RT}$, refilling time; $\mathrm{VP}$, venous pump. and males. This difference also concerned the work of the VP. Males displayed significantly higher values in the parameters mentioned earlier.

No relationships between somatic features and temperature distribution were demonstrated in the sample. Studies examining these parameters in standard conditions have not been found, but tests confirming a reduction in the risks of cardiovascular diseases or diseases associated with body composition disorders as a result of physical exercise are available. ${ }^{20,22}$

A venous PPG is a sensitive, objective test providing information about venous pressure (AVG). Beraldo et al ${ }^{14}$ described the possibility of using PPG in assessing the vascular bed. Similar studies were performed by Jasinski et $\mathrm{al}^{2}$ in females with a diagnosed peripheral arterial disease. The authors observed that, after 8 weeks of physical activities, the quality of venous blood flow in the vessels had improved. According to the subject literature, this test has been fully approved as a noninvasive method in clinical trials in the evaluation of venous vessels of the lower extremities. ${ }^{23}$

Table 7 ANOVA of the right and left extremities within gender groups

\begin{tabular}{llllll}
\hline Variables & Male & & & Female & \\
\cline { 2 - 3 } & $\boldsymbol{F}$ & $\boldsymbol{P}$-value & & $\boldsymbol{F}$ & $\boldsymbol{P}$-value \\
\hline Thermovision & $2.5969 \mathrm{II}$ & $0.1 \mathrm{IIII2}$ & & 0.065508 & $0.79843 \mathrm{I}$ \\
RT & 0.449248 & 0.504672 & & $2.10835 \mathrm{I}$ & 0.149107 \\
VP & 0.887459 & 0.349076 & 0.092310 & 0.761787 \\
Fat & 0.033573 & 0.855094 & & $0.19984 \mathrm{I}$ & 0.655655 \\
Fat mass & 0.000088 & 0.992521 & & 0.007957 & 0.929072 \\
FFM & 0.368853 & 0.545394 & & 0.483952 & 0.487983 \\
Muscle & 0.314175 & 0.576736 & & 0.596890 & 0.441286 \\
Impedance & 0.648784 & 0.422996 & 0.038925 & 0.843932 \\
\hline
\end{tabular}

Abbreviations: ANOVA, analysis of variance; FFM, fat-free mass; $R T$, refilling time; $\mathrm{VP}$, venous pump. 
Analyzing the results of our own research in terms of the distribution of temperature, the dynamics of venous blood flow in lower extremities, and the relationship of these parameters with somatic features in males and females of the University of Third Age, it has been observed that the mean temperature values and the RT and VP values of both males and females did not differ significantly. In assessing particular parameters, it was found that their values were comparable with regard to the right and left LLs. The RT parameter measurements in both males and females showed significant discrepancies from the generally accepted population standards, which is 45 seconds. A reduced value of $\mathrm{VP}$, below the accepted norm of $\sim 40$, was also recorded. The reduced RT results in LLs, obtained from the examined group of males and females, may indicate a malfunction of the working of venous valve compared to the norms, and likewise, the decreased values in the VP parameters may indicate a low efficiency of the VP work.

In the existing literature, one can find research on the assessment of venous system in patients undertaking various forms of physical activity. Studies by Jasinski et al (2015) also looked at the aforementioned issues, assessing LL venous blood flow and body composition in females aged $>50$ years, who performed regular physical activity. After 8 weeks of physical activity, they observed an improved quality of venous blood flow in the vessels. ${ }^{2}$

Jasinski et al (2014) investigated the impact of Nordic walking on the dynamics of venous blood flow in the lower extremities of females using the same test method. They divided the examined females into two groups (15 respondents). The first group was females who practiced Nordic walking, and the second group was females who did not exercise. They found that the dynamics of blood flow in LLs was significantly more favorable in females practicing Nordic walking, while the RT parameters did not change in either group. ${ }^{24}$ The assessment of the dynamics of venous blood flow in lower extremities in our study showed that the RT of venous vessels was similar in males and females and did not differ statistically. There were significant differences in the VP parameters between male and female groups.

\section{Conclusion}

1. The temperature value between the right and left LLs did not differ significantly in males, and it was the same results for females. However, significant temperature differences in both legs were found between the genders. Higher temperature values were recorded in men than in women.
2. There were no relationships established between the dynamics of venous blood flow and the temperature distribution in LLs in both males and females.

3. A positive relationship has been demonstrated between VP and the tissue composition in the lower extremities in females.

\section{Limitations}

The limitations of this study may be the absence of accurate enough assessment of the clinical condition of participant's veins, for example, the Doppler ultrasound test. It is worth continuing the study on a wider group of patients to include the Doppler test. Conducted studies may be useful for the functional diagnosis of LLs in patients with established venous system disorders as well as for monitoring progressive changes in venous vessels.

\section{Disclosure}

The authors report no conflicts of interest in this work.

\section{References}

1. Moura RM, Gomes H, Silva SL, Britto RR, Dias RC. Analysis of the physical and functional parameters of older adults with chronic venous disease. Arch Gerontol Geriatr. 2012;55(3):696-701.

2. Jasinski R, Socha M, Sitko L, Kubicka K, Wozniewski M, Sobiech K. Effect of nordic walking and water aerobics training on body composition and the blood flow in lower extremities in elderly women. J Hum Kinet. 2015;45:113-122.

3. Kugler C, Strunk M, Rudofsky GJ. Venous pressure dynamics of the healthy human leg: role of muscle activity, joint mobility and anthropometric factors. $J$ Vasc Res. 2001;38(1):20-29.

4. Beebe-Dimmer JL, Pfeifer JR, Engle JS, Schottenfeld D. The epidemiology of chronic venous insufficiency and varicose veins. Ann Epidemiol. 2005;15(3):175-184.

5. Callejas JM, Manasanch J; ETIC Group. Epidemiology of chronic venous insufficiency of the lower limbs in the primary care setting. Int Angiol. 2004;23(2):154-163.

6. Robertson L, Evans C, Fowkes FG. Epidemiology of chronic venous disease. Phlebology. 2008;23(3):103-111.

7. Fowkes FG, Evans CJ, Lee AJ. Prevalence and risk factors of chronic venous insufficiency. Angiology. 2001;52(1):5-15.

8. Musil D, Kaletova M, Herman J. Age, body mass index and severity of primary chronic venous disease. Biomed Pap Med Fac Univ Palacky Olomouc Czech Repub. 2011;155(4):367-371.

9. Oganov RG, Savel'ev VS, Shal'nova SA, Kirienko AI, Zolotukhin IA Risk factors of chronic venous insufficiency of the lower extremities and possibilities of its medication in therapeutic practice. Ter Ark. 2006;78:68-72.

10. Bagvathiappan S, Saravanan T, Philip J, et al. Infrared thermal imaging for detection of peripheral vascular disorders. J Med Phys. 2009; 34(1):43-47.

11. Szentkuti A, Kavanagh H, Grazio S. Infrared thermography and image analysis for biomedical use. Period Biol. 2011;113(4):385-392.

12. Debiec-Bak A, Skrzek A, Podbielska H. Application of thermovision for estimation of the optimal and safe parameters of the whole body cryotherapy. J Therm Anal Calorim. 2013;111(3):1853-1859.

13. Chudecka M, Lubkowka A. Temperature changes of selected body's surfaces of handball players in the course of training estimated by thermovision and the study of the impact of physiological and morphological factors on the skin temperature. J Therm Biol. 2010;35:379-385. 
14. Beraldo S, Satpathy A, Dodds SR. A study of the routine use of venous photoplethysmography in a one-stop vascular surgery clinic. Ann R Coll Surg Engl. 2007;89(4):379-383.

15. Kelechi TJ, McNeil RB. A pilot study of venous photoplethysmography screening of patients with chronic venous disorders. Appl Nurs Res. 2010;23(3):178-183.

16. Marston WA. PPG, APG, duplex: which noninvasive tests are most appropriate for the management of patients with chronic venous insufficiency? Semin Vasc Surg. 2002;15(1):13-20.

17. Sam RC, Darvall KA, Adam DJ, Silverman SH, Bradbury AW. Digital venous photoplethysmography in the seated position is a reproducible noninvasive measure of lower limb venous function in patients with isolated superficial venous reflux. J Vasc Surg. 2006;43(2):335-341.

18. Dix FP, Brooke R, McCollum CN. Venous disease is associated with an impaired range of ankle movement. Eur J Vasc Endovasc Surg. 2003; 25(6):556-561.

19. Eberhardt RT, Raffetto JD. Chronic venous insufficiency. Circulation. 2005;111:2398-2409.
20. Padberg FT, Johnston MV, Sisto SA. Structured exercise improves calf muscle pump function in chronic venous insufficiency: a randomized trial. J Vasc Surg. 2004;39(1):79-87.

21. Williams KJ, Ayekoloye O, Moore HM, Davies AH. The calf muscle pump revisited. J Vasc Surg Venous Lymphat Disord. 2014;2(3): 329-334.

22. Lee AJ, Evans CJ, Allan PL, Ruckley CV, Fowkes FG. Lifestyle factors and the risk of varicose veins: Edinburgh Vein Study. J Clin Epidemiol. 2003;56(2):171-179.

23. Kelechi TJ, Bonham PA. Measuring venous insufficiency objectively in the clinical setting. J Vasc Nurs. 2008;26(3):67-73.

24. Jasinski R, Turek J, Rudzińska E, Dabrowska G, Skrzek A. Effects of nordic walking on the lower-limb venous system in Third Age University students. Acta Bio Optica et Informatica Medica. 2014;20(1):39-49.
Clinical Interventions in Aging

\section{Publish your work in this journal}

Clinical Interventions in Aging is an international, peer-reviewed journal focusing on evidence-based reports on the value or lack thereof of treatments intended to prevent or delay the onset of maladaptive correlates of aging in human beings. This journal is indexed on PubMed Central, MedLine,

\section{Dovepress}

CAS, Scopus and the Elsevier Bibliographic databases. The manuscript management system is completely online and includes a very quick and fair peer-review system, which is all easy to use. Visit http://www.dovepress. com/testimonials.php to read real quotes from published authors. 